\title{
Fenugreek extract as an inducer of cellular death via autophagy in human T lymphoma Jurkat cells
}

\author{
Nasser M Al-Daghri ${ }^{1,2^{*}}$, Majed S Alokail ${ }^{1,2}$, Khalid M Alkharfy ${ }^{1,3}$, Abdul Khader Mohammed ${ }^{1,2}$, \\ Sherif H Abd-Alrahman ${ }^{1,2}$, Sobhy M Yakout ${ }^{1,2}$, Osama E Amer ${ }^{1,2}$ and Soundararajan Krishnaswamy ${ }^{1,2}$
}

\begin{abstract}
Background: Drugs used both in classical chemotherapy and the more recent targeted therapy do not have cancer cell specificity and, hence, cause severe systemic side effects. Tumors also develop resistance to such drugs due to heterogeneity of cell types and clonal selection. Several traditional dietary ingredients from plants, on the other hand, have been shown to act on multiple targets/pathways, and may overcome drug resistance. The dietary agents are safe and readily available. However, application of plant components for cancer treatment/prevention requires better understanding of anticancer functions and elucidation of their mechanisms of action. The current study focuses on the anticancer properties of fenugreek, a herb with proven anti-diabetic, antitumor and immune-stimulating functions.
\end{abstract}

Method: Jurkat cells were incubated with 30 to $1500 \mu \mathrm{g} / \mathrm{mL}$ concentrations of $50 \%$ ethanolic extract of dry fenugreek seeds and were followed for changes in viability (trypan blue assay), morphology (microscopic examination) and autophagic marker LC3 transcript level (RT-PCR).

Results: Incubation of Jurkat cells with fenugreek extract at concentrations ranging from 30 to $1500 \mu \mathrm{g} / \mathrm{mL}$ for up to 3 days resulted in cell death in a dose- and time-dependent manner. Jurkat cell death was preceded by the appearance of multiple large vacuoles, which coincided with transcriptional up-regulation of LC3. GC-MS analysis of fenugreek extract indicated the presence of several compounds with anticancer properties, including gingerol (4.82\%), cedrene (2.91\%), zingerone (16.5\%), vanillin (1.52\%) and eugenol (1.25\%).

Conclusions: Distinct morphological changes involving appearance of large vacuoles, membrane disintegration and increased expression of LC3 transcripts indicated that fenugreek extract induced autophagy and autophagy-associated death of Jurkat cells. In addition to the already known apoptotic activation, induction of autophagy may be an additional mechanism underlying the anticancer properties of fenugreek. This is the first report showing fenugreek as an inducer of autophagy in human cells and further work is needed to define the various intermediates of the autophagic pathway.

Keywords: Jurkat cells, Fenugreek, Autophagy, LC3, Autophagic vacuoles, Chemoprevention, Anticancer

\section{Background}

Currently used drugs in cancer treatment cause severe side effects, since the targeted pathways also occur in rapidly dividing normal cells [1]. Newly emerging targeted drugs rely on inhibiting an aberrant tumorpromoting pathway and the heterogeneity of cell types

\footnotetext{
* Correspondence: aldaghri2011@gmail.com

'Biomarkers Research Program, Department of Biochemistry, College of Science King Saud University, PO Box 2455, Riyadh 11451, Saudi Arabia ${ }^{2}$ Prince Mutaib Chair for Osteoporosis Research, College of Science, King Saud University, Riyadh 11451, Saudi Arabia

Full list of author information is available at the end of the article
}

enable cancers develop drug resistance [2]. In addition, genetic instability enables malignant cells to evade inhibitor drugs by secondary mutations in target genes and other genetic changes [2]. As a consequence, progress has been lacking in treating the majority of cancers.

Plant constituents and derivatives hold great promise for cancer prevention and treatment [3-5]. It is now believed that majority of cancers are attributed to environmental and dietary factors and incorporating fruits, vegetables, whole grains and spices in the diet seem to 
reduce the incidence of various cancers [6-9]. Several plant components exhibit superior anticancer properties by overcoming limitations of chemo- and targetedtherapies. Several plant compounds used in traditional medicine are common dietary ingredients and, hence, are considered safe [10]. Plant-derived anticancer agents are broad specific and affect multiple pathways simultaneously. Some plant constituents inhibit tumorpromoting pathways while also activating tumorsuppressor pathways [11,12]. Plant-derived agents have been effective at reducing inflammation and the level of reactive oxygen species (ROS), both common hallmarks of the genesis and progression of all cancers $[13,14]$. Certain plant components capable of killing cancer cells are also known to suppress the tumor promoting actions of immune and other tumor stromal cells [15]. In addition, plant products are less expensive and readily available. Intense research in this area has lead to multiple ongoing clinical trials involving plant derivatives while a few have already been approved for human use [16-18].

Fenugreek is commonly used as a traditional dietary ingredient in India and Egypt, among others. As a medicinal herb it has proven activity against hepatotoxicity [19], diabetes [20,21], hyperlipidemia [22] and cardiovascular diseases $[19,23,24]$. Fenugreek has anticancer properties [25] and has proven to be effective in preventing colon [26] and breast cancers [27]. Fenugreek extract also showed stimulatory effect on immune functions of mice [28].

More research on underlying molecular mechanism of the anticancer activity of fenugreek may lead to its development as an effective therapeutic/chemopreventive agent against various cancers. In this in vitro study we show, for the first time, that fenugreek causes death of T-lymphoma Jurkat cells by inducing autophagy.

\section{Materials}

The cell culture medium (RPMI-1640), fetal bovine serum (FBS) and penicillin-streptomycin were purchased from Gibco-BRL Life Technologies Inc. Jurkat cell line was obtained from American Type Culture Collection (ATCC), USA. Dry seeds of fenugreek, fennel, black pepper, coriander and cumin and sticks of cinnamon used in this study were of food grade and obtained from commercial sellers in Riyadh.

\section{Methods}

\section{Preparation of spice extracts}

$1.5 \mathrm{~g}$ of each of the finely ground spices was suspended in $50 \%$ ethanol in tightly capped bottles and shaken overnight in water bath maintained at $40^{\circ} \mathrm{C}$. The spice suspensions were filtered and the filtrates evaporated under $\mathrm{N}_{2}$ and the dry residues resuspended in $1.5 \mathrm{~mL}$ of
$50 \%$ ethanol to obtain stock solutions of $1 \mathrm{~g} / 1 \mathrm{~mL}$. Further dilutions of fenugreek extract were made by mixing with RPMI medium. Stock solution of fenugreek extract was directly used for GC-MS.

\section{Cell culture}

The Jurkat cell line was cultured in RPMI-1640 medium supplemented with FBS $(10 \%$, v/v), streptomycin $(100 \mu \mathrm{g} / \mathrm{mL})$ and penicillin $(100 \mathrm{U} / \mathrm{mL}) .5 \times 10^{4}$ cells $/ \mathrm{mL}$ were distributed into 24 well plates $(1 \mathrm{~mL} /$ well $)$ and incubated under $5 \% \mathrm{CO}_{2}$ in a humidified atmosphere at $37^{\circ} \mathrm{C}$.

\section{Cell viability assay}

Cell numbers and viabilities were assessed using a hemocytometer based on the ability of the viable cells to exclude trypan blue. Briefly, at the end of treatment period cells in the wells were mixed well and an aliquot of cells were mixed with an equal volume of $0.4 \%$ trypan blue and after 2-3 minutes viable cells were counted by hemocytometer. Viable cells were expressed as a percentage of cells in the untreated well, which at the end of the incubation period was considered $100 \%$. Cell numbers with standard error were averaged from 3 independent experiments.

\section{Morphological evaluation of cells}

Normal and fenugreek extract treated cells were photographed using inverted light microscope at a magnification of 400x.

\section{Quantification of autophagy associated genes expression by RT-PCR}

Total RNA was isolated from Jurkat cells using Qiagen RNeasy mini kit (Qiagen). RNA was reverse transcribed into cDNA using QuantiTect Reverse Transcription Kit (Qiagen). qRT-PCR was performed using SYBR Green PCR kit (Qiagen). Primers used for RT-PCR are shown in Additional file 1: Table S1. The master mixes were pipetted into a 96-well plate followed by the addition of $40 \mathrm{ng}$ of RNA. All samples were analyzed in triplicate. PCR was run using the Bio-Rad Real-Time PCR System which was programmed as follows: (1) $95^{\circ} \mathrm{C}$ stage for 10 minutes, and (3) 40 cycles alternating between $95^{\circ} \mathrm{C}$ for 15 seconds and $60^{\circ} \mathrm{C}$ for 1 minute. Results were analyzed by comparative $\mathrm{Ct}$ method using the formula: $2^{-\Delta \Delta C T} . \Delta C_{T}=C_{T}$ value of gene of interest minus $C_{T}$ value of $\beta$-actin. The $\Delta \Delta C_{T}$ was calculated by subtracting the $\Delta C_{T}$ of the untreated cells from the $\Delta C_{T}$ of the test sample.

Gas chromatography-Mass spectrometry (GC-MS) analysis GC/MS analysis of fenugreek extract was performed using an Agilent 7890 GC System Gas Chromatograph interfaced to a Mass Spectrometer (GC/MS) equipped 
with a VF-5ms capillary column $(30 \mathrm{~m} \times 0.25 \mathrm{~mm}$ ID $\times$ $0.25 \mu \mathrm{m})$. GC/MS detection was achieved using an electron ionization system with $70 \mathrm{eV}$ ionization energy. Helium $(99.999 \%)$ was used as carrier gas at a constant flow rate of $1 \mathrm{~mL} / \mathrm{min}$. An injection volume of $2 \mu \mathrm{L}$ was employed in splitless mode. Injector and ion-source were maintained at $250^{\circ} \mathrm{C}$ and $280^{\circ} \mathrm{C}$, respectively. The oven temperature was raised from $100^{\circ} \mathrm{C}$ (isothermal for $2 \mathrm{~min}$.) to $200^{\circ} \mathrm{C}$ at a rate of $5^{\circ} \mathrm{C} / \mathrm{min}$ and further up to $240^{\circ} \mathrm{C}$ by $10^{\circ} \mathrm{C} / \mathrm{min}$ and maintained at $240^{\circ} \mathrm{C}$ for $11 \mathrm{~min}$. Total GC running time was 40 minutes. The relative amount of each constituent was calculated by measuring corresponding peak area and represented as a percentage of the sum of areas of all peaks. MS Workstation 7.0 software was used to analyze mass spectra and chromatograms.

\section{Statistical analysis}

Data was analyzed using the Microsoft Excel (Microsoft Office 2007). Variables were presented as percentages (\%).

\section{Results}

Screening spices for cytotoxicity against Jurkat cells Jurkat cells were incubated with 50\% ethanolic extracts of 6 different spices at $1 \mathrm{mg} / \mathrm{mL}$ for $72 \mathrm{hr}$ and viable cells counted at the end by trypan blue exclusion assay (Figure 1). Cinnamon and fenugreek treatment resulted in death of $100 \%$ and $99 \%$ of cells, respectively. Only $25 \%$ viable cells were found after cumin treatment. Ginger, black pepper and fennel extracts showed no effect on the viability of Jurkat cells. Due to the distinct morphological changes induced by fenugreek extract it was chosen for further studies.
Effect of fenugreek extract on the viability of Jurkat cells Jurkat cells were incubated with 30 to $1500 \mu \mathrm{g} / \mathrm{mL}$ of fenugreek extract for $48 \mathrm{hr}$ and viable cells counted at the end. Percentage of viable cells showed a steady decrease with increasing concentrations of fenugreek (Figure 2A). Cell death was observed even at $30 \mu \mathrm{g} / \mathrm{mL}$ and most of the cells were lost at $1500 \mu \mathrm{g} / \mathrm{mL}$. Jurkat cells incubated with 250, 500 and $1000 \mu \mathrm{g} / \mathrm{mL}$ concentrations of fenugreek extract for up to $72 \mathrm{hr}$ indicated dose and time dependent decrease in viability (Figure 2B). In this period, untreated cells almost doubled in number in a day for 2 days and continued to grow significantly on the $3^{\text {rd }}$ day. At all the three concentrations of fenugreek most of the cells were lost at $72 \mathrm{hr}$. Decrease in viable cells caused by fenugreek extract was not matched by a corresponding increase in dead cells by the trypan blue assay and this may be due to the complete disintegration of plasma membrane as shown in the following sections.

\section{Morphological changes induced by fenugreek in Jurkat cells}

Incubation of Jurkat cells with fenugreek extract resulted in the appearance of vacuoles at all concentrations of fenugreek tested (Figure 3A). These vacuoles were large enough to be seen directly by light microscope. Vacuoles appeared from as early as $16 \mathrm{hr}$ of incubation of cells with higher concentrations of fenugreek $(>250 \mu \mathrm{g} / \mathrm{mL})$. Some cells had a single large vacuole occupying most of the cell space and others had more. The vacuoles appeared highly spherical (Figure 3B). Appearance of multiple large vacuoles was followed by disintegration of plasma membrane (Figure 4). With increasing

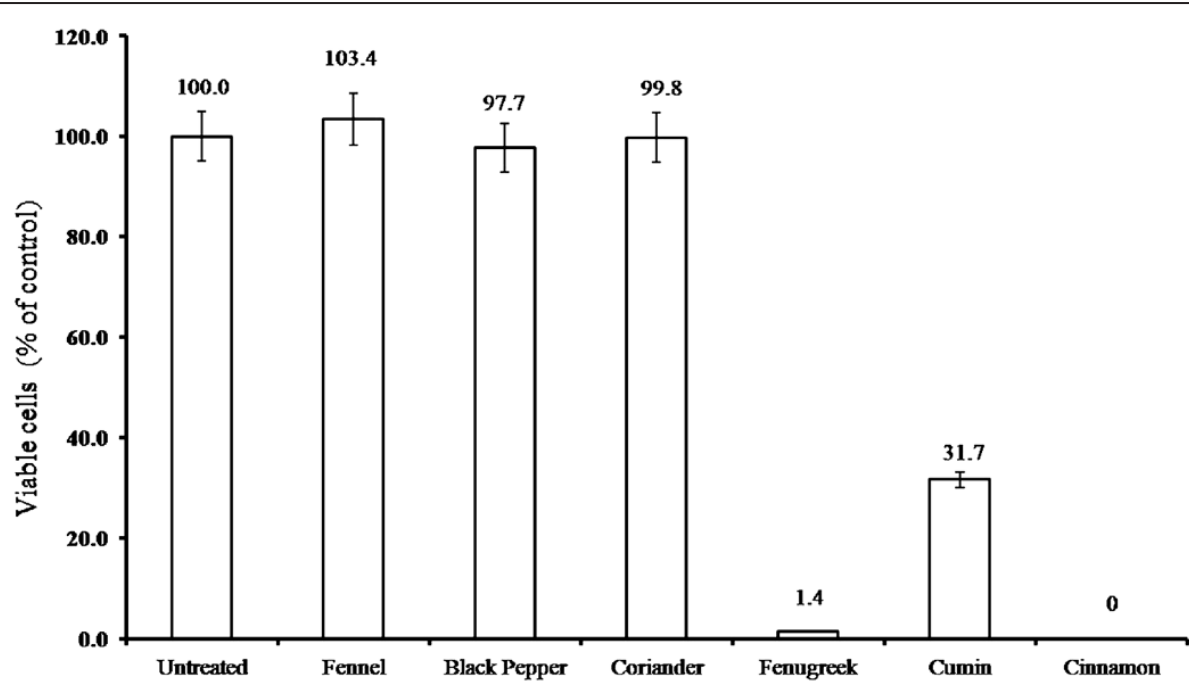

Figure 1 Effect of different spice extracts on viability of Jurkat cells. Jurkat cells were incubated with $1 \mathrm{mg} / \mathrm{mL}$ of $50 \%$ ethanolic extracts of different spices for $72 \mathrm{hr}$. Viable cells were counted by trypan blue assay as described in methods. Fenugreek and cinnamon extracts were highly cytotoxic and affected the viability of most of the cells. 

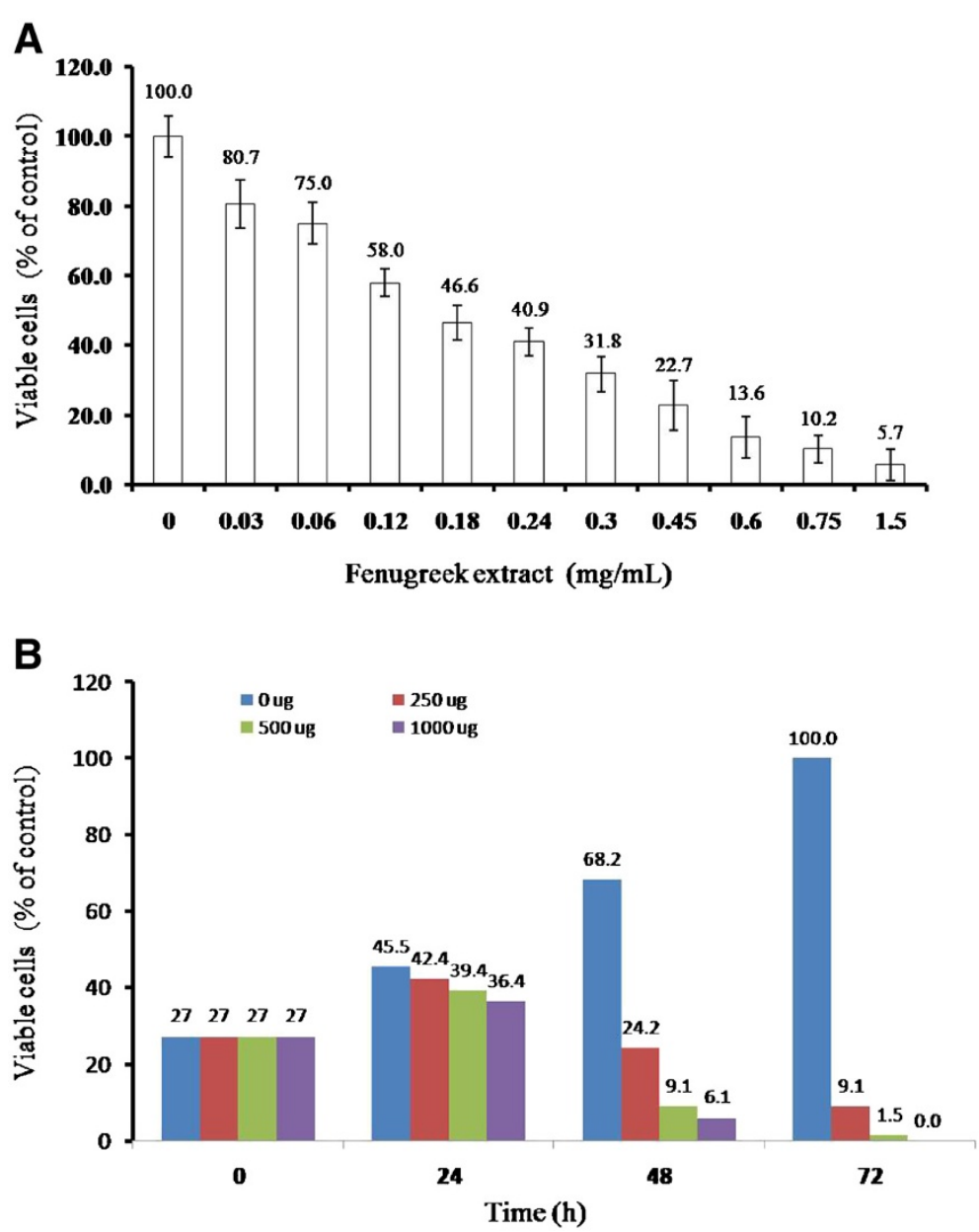

Figure 2 Fenugreek extract inhibits Jurkat cell proliferation. (A) Viability of Jurkat cells incubated with 30 to $1500 \mu \mathrm{g} / \mathrm{mL}$ of fenugreek extract was determined after $48 \mathrm{hr}$ by trypan blue assay. Death of Jurkat cells occurred at all the tested concentrations of fenugreek and followed a dose-dependent pattern. (B) Time-dependent increase in death of Jurkat cells upon incubation with various concentrations of fenugreek.

concentrations of extract, some of the cellular contents could be seen in the absence of distinct plasma membrane and even these cytoplasmic cell structures disappeared over time, indicating complete cell lysis. Whole cell lysis was also indicated by the absence of dead cells upon staining with trypan blue even through the number of viable cells showed large declines.

\section{Fenugreek extract induced up-regulation of LC3}

Jurkat cells were incubated with 250, 500 and $1000 \mu \mathrm{g} / \mathrm{mL}$ concentrations of fenugreek extract for 24 and $48 \mathrm{hr}$. RT-PCR analysis of RNA from these cells indicated upregulation of LC3 relative to $\beta$-actin in samples harvested at $48 \mathrm{hr}$ and the increase depended on the concentration of fenugreek (Figure 5). A 2.5 fold increase in LC3 transcript was found in cells treated with $1000 \mu \mathrm{g} / \mathrm{mL}$ of fenugreek compared to untreated cells. However, the quantity of LC3 transcripts did not differ much from the control at the end of $24 \mathrm{hr}$.

\section{GC-MS analysis of fenugreek extract}

GC-MS analysis of fenugreek extract resolved into 34 peaks corresponding to a similar number of unique compounds. Gingerol (4.82\% of the total), cedrene ( $2.91 \%)$, zingerone $(16.5 \%)$, vanillin $(1.52 \%), \beta$-bisabolene $(1.25 \%)$ and eugenol $(1.25 \%)$ were some of the anticancer compounds identified by GC-MS in this extract (Table 1).

\section{Discussion}

Plant derivatives have great promise as anticancer agents. In this study, low concentrations of fenugreek extract was found to induce death of Jurkat cells, a commonly used cell line model to understand anticancer functions and underlying mechanisms of exploratory drugs or compounds. Fenugreek extract affected the viability of Jurkat cells in a dose- and time-dependent manner. Fenugreek extract-induced death was preceded by dramatic morphological changes involving the 

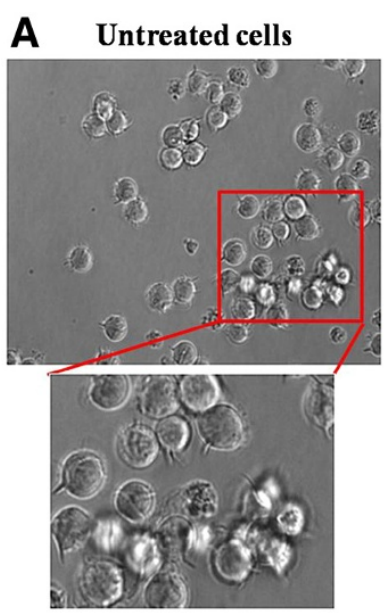

Fenugreek at $1 \mathrm{mg} / \mathrm{mL}$

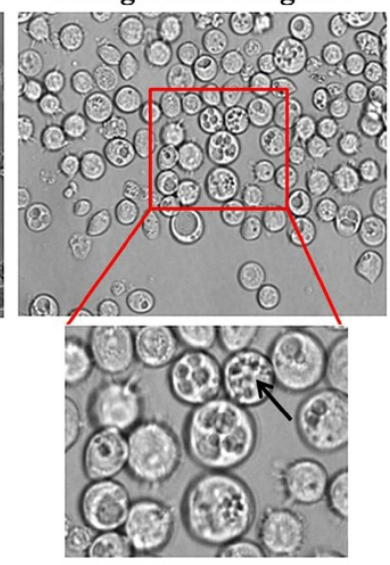

B

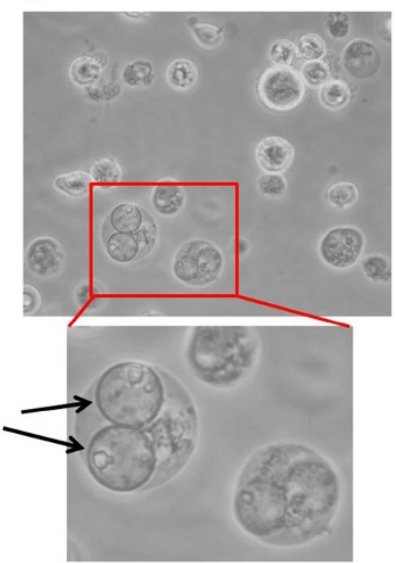

Figure 3 Fenugreek extract induced vacuoles in Jurkat cells. Overnight incubation of Jurkat cells with $1 \mathrm{mg} / \mathrm{mL}$ of fenugreek extract induced distinct vacuoles. (A) The number of vacuoles range from 1 to several per cell. Arrow points to multiple vacuoles in a cell. (B) Arrows point to Jurkat cells possessing two large spherical vacuoles. Pictures represent inverted light microscopic images taken at 400x magnification.

appearance of multiple large vacuoles and transcriptional up-regulation of LC3, both of which imply activation of autophagy. Results from this study imply autophagy as a novel mechanism by which fenugreek may bring about death of preneoplastic/neoplastic cells. T-cell lymphoid malignancies are a group of highly aggressive diseases that are generally resistant to current treatment modalities and results from this study indicate benefits of fenugreek as a potential therapeutic. Further, induction of autophagy may be a general anticancer mechanism underlying chemopreventive/therapeutic function of fenugreek.

Anticancer properties of fenugreek or its constituents involve multiple functional and molecular targets. Fenugreek induced apoptosis in a wide variety of tumor cell lines, including those of human colon [26], osteosarcoma [29], leukemia [30], breast [31,32], and liver [33]. Fenugreek blocked migration and invasion by reducing matrix metalloproteinase expression in human prostate cancer PC-3 cells [34], decreased nitric oxide (NO) and prostaglandin production by suppressing iNOS and COX-2, respectively, in an osteosarcoma cell line [35]. Fenugreek blocked activation of NF-KB, I kappa B kinase and $\mathrm{AKT}$ and suppressed the production of various proinflammatory cytokines like IL-6, IL-1 and TNF- $\alpha$ by cancer cells $[31,36]$. An earlier study noted the formation of cytoplasmic vacuoles in breast tumor tissue of 7 , 12-dimethylbenz $(\alpha)$ anthracene (DBMA) treated rats upon feeding of fenugreek compared to control [27]. To our knowledge, ours is the first report to show death of human cancer cells by fenugreek-induced autophagy.

Apoptosis and autophagy are important pathways designed to cause programmed death of stressed cells and cancers suppress both these pathways and evade death. Autophagy has been defined as a process of transport of cytoplasmic contents to the lysozomes in double membrane compartments, called vacuoles [37].

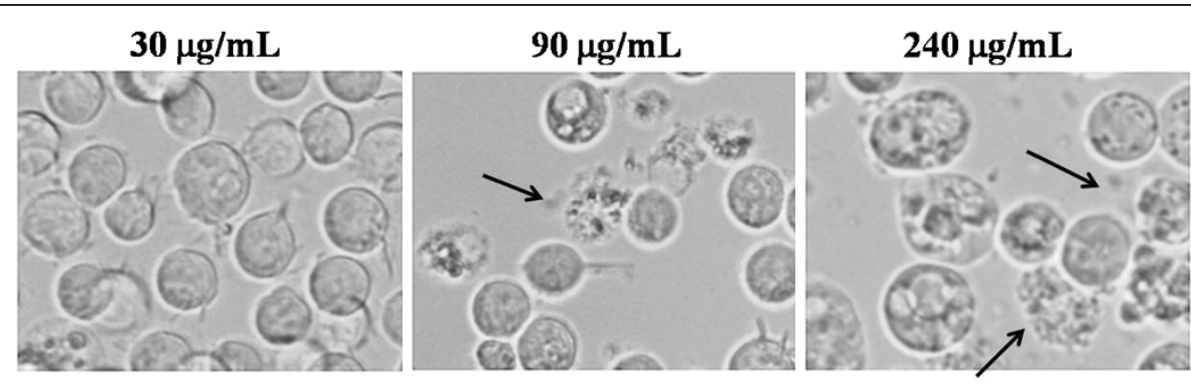

Figure 4 Fenugreek extract induced plasma membrane rupture and total cell lysis. Increasing concentrations of fenugreek extract after $48 \mathrm{hr}$ caused morphological changes leading to cell death. Disappearance of cell shape by rupture of plasma membrane was seen at higher concentrations of fenugreek extract. Arrows point to cellular membranes undergoing rupture. Pictures represent inverted light microscopic images taken at 400x magnification. 


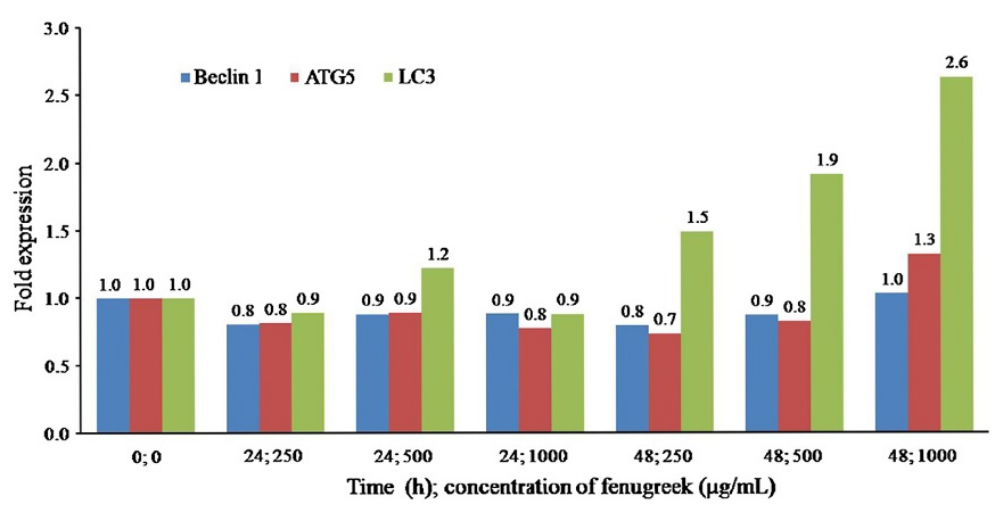

Figure 5 Transcriptional regulation of autophagic genes by fenugreek. Jurkat cells incubated with 250, 500 and $1000 \mu \mathrm{g} / \mathrm{mL}$ of fenugreek extract were quantitatively analyzed for transcripts of autophagic pathway genes beclin 1, ATG5 and LC3 by RT-PCR using $\beta$-actin as internal reference. Dose dependent increase in LC3 transcripts was found in cells incubated for $48 \mathrm{hr}$ while no significant changes were observed for beclin 1 and ATG5.

Autophagy is a physiological response to stress and has been suggested to enable cells to adapt and survive and, hence, is considered a pro-survival mechanism [38]. Autophagy has also been defined as a highly conserved process of programmed cell death [39] and its activation causes cell death [40]. Defective regulation of autophagy in cancers suggests that autophagy is a true tumorsuppressor pathway $[41,42]$ and this is further supported by the fact that several commonly activated oncogenes (for example, those encoding PI3K, TOR, Bcl-2) inhibit autophagy, whereas commonly mutated or epigenetically silenced tumor suppressor genes (such as those encoding p53, PTEN, TSC1/TSC2) stimulate autophagy [43].

Several studies have used electron microscopic methods to detect autophagic vacuoles. However, fenugreekinduced vacuoles in Jurkat cells were large and distinct and could be directly seen using an inverted light microscope. This study established the vacuolization as an autophagic process from the transcriptional upregulation LC3. LC3 plays a critical role in autophagy and is considered suitable marker of this process [44]. In the present study, fenugreek extract increased LC3 transcript level with increasing concentrations of fenugreek extract over a period of $48 \mathrm{~h}$. Harmol, a beta carotenoid, induced death of lung cancer cells A549 was associated with increased expression of LC3 [45] and siRNA knockdown of LC3 resulted in blockade of cell death, which, in turn, served to prove that harmol-induced autophagy was only a death mechanism [45]. Transcripts of beclin 1 and ATG5, the other autophagic pathway genes, did not show any decline in our fenugreek-treated Jurkat cells and this was similar to harmol-treated A549 cells which failed to show any changes in the expression and phosphorylation of beclin 1 [45].

Some health benefits of various medicinal plants or their constituents have been attributed to their ability to

Table 1 Anticancer compounds of $50 \%$ ethanolic extract of fenugreek seeds identified by GC-MS

\begin{tabular}{|c|c|c|c|c|}
\hline $\begin{array}{l}\text { Retention } \\
\text { Time (min.) }\end{array}$ & $\begin{array}{l}\text { Compound } \\
\text { Name }\end{array}$ & Formula & $\%$ of Total & ${ }^{*}$ Activity \\
\hline 8.54 & 4-Vinylguaiacol & $\mathrm{C} 9 \mathrm{H} 10 \mathrm{O} 2$ & 1.36 & $\begin{array}{l}\text { Anti-edemic; anti-inflammatory; anti-prostaglandin; } \\
\text { prostaglandin-synthesis-inhibitor }\end{array}$ \\
\hline 9.452 & Eugenol & $\mathrm{C} 10 \mathrm{H} 12 \mathrm{O} 2$ & 1.25 & $\begin{array}{l}\text { Antibacterial; anti-inflammatory; antioxidant; antioxidant; } \\
\text { antitumor; cancer-preventive }\end{array}$ \\
\hline 10.463 & Vanillin & $\mathrm{C} 8 \mathrm{H} 8 \mathrm{O} 3$ & 1.52 & $\begin{array}{l}\text { Anticancer; antimutagenic; antioxidant; antitumor; } \\
\text { antitumor-promoter; antiviral; cancer-preventive; } \\
\text { fungicide; immunosuppressant }\end{array}$ \\
\hline 13.05 & $\beta$-Bisabolene & $\mathrm{C} 15 \mathrm{H} 24$ & 1.25 & Anticancer \\
\hline 13.488 & Cedrene & $\mathrm{C} 15 \mathrm{H} 24$ & 2.91 & Cancer-preventive \\
\hline 16.486 & Zingerone & $\mathrm{C} 11 \mathrm{H} 14 \mathrm{O} 3$ & 12.03 & Anti-inflammatory, antioxidant \\
\hline 29.508 & Gingerol & $\mathrm{C} 17 \mathrm{H} 2604$ & 4.82 & $\begin{array}{l}\text { Antiemetic; anti-hepatotoxic; antihistaminic; anti-inflammatory; } \\
\text { antioxidant; antiseptic; anti-thromboxane; cancer-preventive; } \\
\text { cyclooxygenase-inhibitor; hepatoprotective }\end{array}$ \\
\hline
\end{tabular}


induce autophagy in diseased cells [46]. Experiments performed to measure the autophagy-inducing ability of several plant constituents, for eg., fisetin (found in tomatoes, apples, onions, and grapes), genistein (soybean) and quercetin (apple skins and red onions), report opposing findings (induction or suppression) resulting in reduced clarity on the beneficial effect of autophagy in cancer treatment. These contradictory results have been attributed to several factors, such as different methods employed to measure autophagy and the use of different cell types, such as cancerous cells versus normal cells [46]. Also, autophagy, at low levels, was suggested to serve a pro-survival role in tumors [47]. However, results from our study revealed increased production of autophagic markers and decreased viability to be associated with increasing concentrations of fenugreek implying only an anti-proliferative /pro-death function for autophagy at all concentrations of fenugreek extract. Results from our study support the notion that fenugreekinduced autophagy in Jurkat cells could only be an antitumor function.

Some of the components of fenugreek extract identified by GC-MS in our study have already been shown to possess significant anticancer activities and these include gingerol [14], cedrene [48], zingerone [49], vanillin [50], and eugenol [51-53]. Future studies will be designed to identify the specific compound(s) responsible for induction autophagy.

The cytotoxic effects of fenugreek are limited, mostly, to cancer cells $[25,32]$. Bioavailability of therapeutic components of fenugreek, unlike curcumin, is high as seen from its hepatoprotective effect from various in vivo studies $[54,55]$. Feeding studies have indicated tolerance and absence of any toxicities of up to several grams of fenugreek per day over several weeks [56].

The authors acknowledge some limitations. The study included a limited type and number of cell lines and lacked specific assays to confirm apoptosis and autophagy. Nevertheless, the present study identified autophagy as a new mechanism by which fenugreek may exert its therapeutic/chemoprevention/anticancer function.

\section{Conclusion}

Fenugreek induced autophagy in Jurkat cells in a time and dose dependent manner, as indicated by morphological changes and up-regulated LC3. GC-MS analysis of the fenugreek extract identified several compounds having anticancer properties. Thus, due to its ability induce death of Jurkat cells by autophagy at low concentrations and lower level of non-specific toxicity, fenugreek may serve as a potential therapeutic in the treatment of lymphoid malignancy.

\section{Additional file}

Additional file 1: Table S1. Primers used for analysis of expression of autophagy associated genes by RT-PCR.

\section{Competing interests}

The authors have no competing interests to declare.

\section{Authors' contributions}

SK and OEA performed cell culture experiments. AKM conducted RT-PCR quantifications. SHA and SMY were involved in preparation of spice extracts and GC-MS analysis. SK, MSA and KMA designed the experiments and helped to draft the manuscript. NMD conceived and coordinated the study. All the authors have read and approved the final manuscript.

\section{Acknowledgements}

The authors are grateful for the Prince Mutaib Chair for Osteoporosis Research, King Saud University for funding and technical assistance.

\section{Author details}

${ }^{1}$ Biomarkers Research Program, Department of Biochemistry, College of Science King Saud University, PO Box 2455, Riyadh 11451, Saudi Arabia. ${ }^{2}$ Prince Mutaib Chair for Osteoporosis Research, College of Science, King Saud University, Riyadh 11451, Saudi Arabia. ${ }^{3}$ Department of Clinical Pharmacy, College of Pharmacy, King Saud University, Riyadh 11451, Saudi Arabia.

Received: 5 May 2012 Accepted: 16 October 2012

Published: 30 October 2012

\section{References}

1. Gibbs JB: Mechanism-based target identification and drug discovery in cancer research. Science 2000, 287(5460):1969-1973.

2. Richardson ME, Siemann DW: Tumor cell heterogeneity: impact on mechanisms of therapeutic drug resistance. Int J Radiat Oncol Biol Phys 1997, 39(4):789-795.

3. Balunas MJ, Kinghorn AD: Drug discovery from medicinal plants. Life Sci 2005, 78(5):431-441.

4. Pezzuto JM: Plant-derived anticancer agents. Biochem Pharmacol 1997, 53(2):121-133.

5. Abdel-Hamid NM, Nazmy MH, Mahmoud AW, Fawzy MA, Youssof M: A survey on herbal management of hepatocellular carcinoma. World J Hepatol 2011, 3(7):175-183.

6. Aune D, Chan DS, Lau R, Vieira R, Greenwood DC, Kampman E, Norat T: Dietary fibre, whole grains, and risk of colorectal cancer: systematic review and dose-response meta-analysis of prospective studies. BMJ 2011, 343:d6617.

7. Steinmetz KA, Potter JD: Vegetables, fruit, and cancer prevention: a review. J Am Diet Assoc 1996, 96(10):1027-1039.

8. Van Duyn MA, Pivonka E: Overview of the health benefits of fruit and vegetable consumption for the dietetics professional: selected literature. J Am Diet Assoc 2000, 100(12):1511-1521.

9. Aggarwal BB, Van Kuiken ME, lyer LH, Harikumar KB, Sung B: Molecular targets of nutraceuticals derived from dietary spices: potential role in suppression of inflammation and tumorigenesis. Exp Biol Med (Maywood) 2009, 234(8):825-849.

10. Haque N, Salma U, Nurunnabi TR, Haque AK, Mukti IJ, Pervin S, Nahar R: Lifestyle related causes of cancer and chemoprevention through phytonutrients. Pak J Biol Sci 2010, 13(19):916-926.

11. Guilford JM, Pezzuto JM: Natural products as inhibitors of carcinogenesis. Expert Opin Investig Drugs 2008, 17(9):1341-1352.

12. Surh YJ: Cancer chemoprevention with dietary phytochemicals. Nat Rev Cancer 2003, 3(10):768-780.

13. Gupta SC, Kim JH, Prasad S, Aggarwal BB: Regulation of survival, proliferation, invasion, angiogenesis, and metastasis of tumor cells through modulation of inflammatory pathways by nutraceuticals. Cancer Metastasis Rev 2010, 29(3):405-434.

14. Sung B, Prasad S, Yadav VR, Aggarwal BB: Cancer cell signaling pathways targeted by spice-derived nutraceuticals. Nutr Cancer 2012, 64(2):173-197. 
15. Jagetia GC, Aggarwal BB: "Spicing up" of the immune system by curcumin. J Clin Immunol 2007, 27(1):19-35.

16. Butler MS: Natural products to drugs: natural product-derived compounds in clinical trials. Nat Prod Rep 2008, 25(3):475-516.

17. Dhillon RAW N, Abbruzzese JL, Hong DS, Camacho LH, Li L, Braiteh F, Kurzrock R: Phase II clinical trial of curcumin in patients with advanced pancreatic cancer. J Clin Oncol (Meeting Abstracts) 2006, 24(18S):14151.

18. Sashidhara KV, White KN, Crews P: A selective account of effective paradigms and significant outcomes in the discovery of inspirational marine natural products. J Nat Prod 2009, 72(3):588-603.

19. Ulbricht C, Basch E, Burke D, Cheung L, Ernst E, Giese N, Foppa I, Hammerness P, Hashmi S, Kuo G, et al: Fenugreek (Trigonella foenum-graecum L. Leguminosae): an evidence-based systematic review by the natural standard research collaboration. $J$ Herb Pharmacother 2007, 7(3-4):143-177.

20. Prabhakar PK, Doble M: Mechanism of action of natural products used in the treatment of diabetes mellitus. Chin J Integr Med 2011, 17(8):563-574.

21. Haque N, Salma U, Nurunnabi TR, Uddin MJ, Jahangir MF, Islam SM, Kamruzzaman M: Management of type 2 diabetes mellitus by lifestyle, diet and medicinal plants. Pak J Biol Sci 2011, 14(1):13-24.

22. Hasani-Ranjbar S, Nayebi N, Moradi L, Mehri A, Larijani B, Abdollahi M The efficacy and safety of herbal medicines used in the treatment of hyperlipidemia; a systematic review. Curr Pharm Des 2010, 16(26):2935-2947.

23. Sirtori CR, Galli C, Anderson JW, Sirtori E, Arnoldi A: Functional foods for dyslipidaemia and cardiovascular risk prevention. Nutr Res Rev 2009, 22(2):244-261.

24. Dwivedi S, Aggarwal A: Indigenous drugs in ischemic heart disease in patients with diabetes. J Altern Complement Med 2009, 15(11):1215-1221.

25. Shabbeer S, Sobolewski M, Anchoori RK, Kachhap S, Hidalgo M, Jimeno A, Davidson N, Carducci MA, Khan SR: Fenugreek: a naturally occurring edible spice as an anticancer agent. Cancer Biol Ther 2009, 8(3):272-278.

26. Raju J, Patlolla JM, Swamy MV, Rao CV: Diosgenin, a steroid saponin of Trigonella foenum graecum (Fenugreek), inhibits azoxymethane-induced aberrant crypt foci formation in F344 rats and induces apoptosis in HT-29 human colon cancer cells. Cancer Epidemiol Biomarkers Prev 2004, 13(8):1392-1398.

27. Amin A, Alkaabi A, Al-Falasi S, Daoud SA: Chemopreventive activities of Trigonella foenum graecum (Fenugreek) against breast cancer. Cell Biol Int 2005, 29(8):687-694.

28. Bin-Hafeez B, Haque R, Parvez S, Pandey S, Sayeed I, Raisuddin S: Immunomodulatory effects of fenugreek (Trigonella foenum graecum L.) extract in mice. Int Immunopharmacol 2003, 3(2):257-265.

29. Corbiere C, Liagre B, Bianchi A, Bordji K, Dauca M, Netter P, Beneytout JL: Different contribution of apoptosis to the antiproliferative effects of diosgenin and other plant steroids, hecogenin and tigogenin, on human 1547 osteosarcoma cells. Int J Oncol 2003, 22(4):899-905.

30. Liu MJ, Wang Z, Ju Y, Wong RN, Wu QY: Diosgenin induces cell cycle arrest and apoptosis in human leukemia $\mathrm{K} 562$ cells with the disruption of Ca2+ homeostasis. Cancer Chemother Pharmacol 2005, 55(1):79-90.

31. Srinivasan S, Koduru S, Kumar R, Venguswamy G, Kyprianou N, Damodaran C: Diosgenin targets Akt-mediated prosurvival signaling in human breast cancer cells. Int J Cancer 2009, 125(4):961-967.

32. Khoja KK, Shaf G, Hasan TN, Syed NA, Al-Khalifa AS, Al-Assaf AH, Alshatwi AA: Fenugreek, a naturally occurring edible spice, kills MCF-7 human breast cancer cells via an apoptotic pathway. Asian Pac J Cancer Prev 2011, 12(12):3299-3304.

33. Li F, Fernandez PP, Rajendran P, Hui KM, Sethi G: Diosgenin, a steroidal saponin, inhibits STAT3 signaling pathway leading to suppression of proliferation and chemosensitization of human hepatocellular carcinoma cells. Cancer Lett 2010, 292(2):197-207.

34. Chen PS, Shih YW, Huang HC, Cheng HW: Diosgenin, a steroidal saponin, inhibits migration and invasion of human prostate cancer PC-3 cells by reducing matrix metalloproteinases expression. PLoS One 2011, 6(5):e20164.

35. Varjas T, Nowrasteh G, Budan F, Horvath G, Cseh J, Gyongyi Z, Makai S, Ember I: The effect of fenugreek on the gene expression of arachidonic acid metabolizing enzymes. Phytother Res 2011, 25(2):221-227.

36. Shishodia S, Aggarwal BB: Diosgenin inhibits osteoclastogenesis, invasion, and proliferation through the downregulation of Akt, I kappa B kinase activation and NF-kappa B-regulated gene expression. Oncogene 2006, 25(10):1463-1473.

37. Klionsky DJ, Emr SD: Autophagy as a regulated pathway of cellular degradation. Science 2000, 290(5497):1717-1721.

38. Chen N, Debnath J: Autophagy and tumorigenesis. FEBS Lett 2010, 584(7):1427-1435.

39. Clarke PG: Developmental cell death: morphological diversity and multiple mechanisms. Anat Embryol (Berl) 1990, 181(3):195-213.

40. Vicencio JM, Galluzzi L, Tajeddine N, Ortiz C, Criollo A, Tasdemir E, Morselli E, Ben Younes A, Maiuri MC, Lavandero S, et al: Senescence, apoptosis or autophagy? When a damaged cell must decide its path--a mini-review. Gerontology 2008, 54(2):92-99.

41. Levine B, Kroemer G: Autophagy in the pathogenesis of disease. Cell 2008, 132(1):27-42.

42. Mathew R, Karantza-Wadsworth V, White E: Role of autophagy in cancer. Nat Rev Cancer 2007, 7(12):961-967.

43. Botti J, Djavaheri-Mergny M, Pilatte Y, Codogno P: Autophagy signaling and the cogwheels of cancer. Autophagy 2006, 2(2):67-73.

44. Tanida I, Ueno T, Kominami E: LC3 conjugation system in mammalian autophagy. Int I Biochem Cell Biol 2004, 36(12):2503-2518.

45. Abe A, Yamada H, Moriya S, Miyazawa K: The beta-carboline alkaloid harmol induces cell death via autophagy but not apoptosis in human non-small cell lung cancer A549 cells. Biol Pharm Bull 2011, 34(8):1264-1272

46. Hannigan AM, Gorski SM: Macroautophagy: the key ingredient to a healthy diet? Autophagy 2009, 5(2):140-151.

47. Hu YL, Delay M, Jahangiri A, Molinaro AM, Rose SD, Carbonell WS, Aghi MK: Hypoxia-induced autophagy promotes tumor cell survival and adaptation to antiangiogenic treatment in glioblastoma. Cancer Res 2012, 72(7):1773-1783.

48. Malkinson AM, Beer DS: Pharmacologic and genetic studies on the modulatory effects of butylated hydroxytoluene on mouse lung adenoma formation. J Natl Cancer Inst 1984, 73(4):925-933.

49. Kundu JK, Na HK, Surh YJ: Ginger-derived phenolic substances with cancer preventive and therapeutic potential. Forum Nutr 2009, 61:182-192

50. Deb J, Dibra H, Shan S, Rajan S, Manneh J, Kankipati CS, Perry CJ, Nicholl ID: Activity of aspirin analogues and vanillin in a human colorectal cancer cell line. Oncol Rep 2011, 26(3):557-565.

51. Vidhya $N$, Devaraj SN: Induction of apoptosis by eugenol in human breast cancer cells. Indian J Exp Biol 2011, 49(11):871-878.

52. Jaganathan SK, Mazumdar A, Mondhe D, Mandal M: Apoptotic effect of eugenol in human colon cancer cell lines. Cell Biol Int 2011, 35(6):607-615.

53. Manikandan P, Murugan RS, Priyadarsini RV, Vinothini G, Nagini S: Eugenol induces apoptosis and inhibits invasion and angiogenesis in a rat model of gastric carcinogenesis induced by MNNG. Life Sci 2010, 86(25-26):936-941.

54. Sakr SA, Abo-El-Yazid SM: Effect of fenugreek seed extract on adriamycin-induced hepatotoxicity and oxidative stress in albino rats. Toxicol Ind Health 0748233711425076 2011, doi:10.1177/0748233711425076.

55. Sushma N, Devasena T: Aqueous extract of Trigonella foenum graecum (fenugreek) prevents cypermethrin-induced hepatotoxicity and nephrotoxicity. Hum Exp Toxicol 2010, 29(4):311-319.

56. Muraki E, Hayashi Y, Chiba H, Tsunoda N, Kasono K: Dose-dependent effects, safety and tolerability of fenugreek in diet-induced metabolic disorders in rats. Lipids Health Dis 2011, 10:240.

\section{doi:10.1186/1472-6882-12-202}

Cite this article as: Al-Daghri et al.: Fenugreek extract as an inducer of cellular death via autophagy in human T lymphoma Jurkat cells. BMC Complementary and Alternative Medicine 2012 12:202. 